Arq. Bras. Med. Vet. Zootec., v.70, n.4, p.1257-1265, 2018

\title{
Sistemas de aleitamento artificial para bezerros em condições tropicais
}

\author{
[Artificial feeding systems for calves in tropical conditions] \\ J.B. Ferreira Filho ${ }^{1}$, J.A.G. Azevedo ${ }^{1}$, A.B. Santos $^{1}$, L.L. Souza ${ }^{1}$, L.T. Costa ${ }^{2}$,L.G.R. Pereira ${ }^{3}$, \\ F.N.F. Cruz ${ }^{1}$, C.A. Santanta ${ }^{1}$, R.W. Cabala ${ }^{4}$, G.A. Oliveira ${ }^{1}$ \\ ${ }^{1}$ Universidade Estadual de Santa Cruz -Ilhéus, BA \\ ${ }^{2}$ Universidade Estadual do Sudoeste da Bahia -Itapetinga, BA \\ ${ }^{3}$ Empresa Brasileira de Pesquisa Agropecuária -Juiz de Fora, MG \\ ${ }^{4}$ Universidade Federal de Minas Gerais -Belo Horizonte, MG
}

\begin{abstract}
RESUMO
Objetivou-se avaliar o desempenho bioeconômico de bezerros, nos primeiros 60 dias de vida, submetidos a três sistemas de aleitamento. Foram utilizados 24 bezerros (Holandês x Guzerá), sendo 12 machos e 12 fêmeas, com peso inicial de $32,25 \pm 4,8 \mathrm{~kg}$ para as fêmeas e $36,92 \pm 6,8 \mathrm{~kg}$ para os machos. Os animais foram distribuídos em delineamento inteiramente ao acaso, em esquema fatorial ( $3 \times 2$ ). Os bezerros receberam água à vontade e seis litros de sucedâneo lácteo por dia, durante 60 dias, em três estratégias diferentes, denominadas sistema de aleitamento (SA30: 3 litros de sucedâneo lácteo, duas vezes ao dia, até 30 dias de idade; SA45: 3 litros de sucedâneo lácteo, duas vezes ao dia, até 45 dias de idade; SA49: 3 litros de sucedâneo lácteo, duas vezes ao dia, até 49 dias de idade). Os sistemas de aleitamento estudados não apresentaram diferença estatística $(\mathrm{P}>0,05)$ para o consumo e a digestibilidade de nutrientes, com exceção para o consumo de matéria orgânica (MO) e extrato etéreo $(\mathrm{EE})$. Verificou-se interação $(\mathrm{P}<0,05)$ entre o sistema de aleitamento e a classe sexual para os consumos de MO e EE, bem como para o ganho médio diário, em que os machos do SA 49 apresentaram maiores médias em relação ao SA 30 . O desempenho bioeconômico de bezerros machos do sistema de aleitamento 49 foi superior e apresentou a melhor relação custo-benefício entre os sistemas estudados.
\end{abstract}

Palavras-chave: sucedâneo lácteo, bovinos,consumo,desempenho

\begin{abstract}
The objective of this study was to evaluate the bioeconomic performance of calves in the first 60 days of life submitted to three feeding systems. Twenty-four calves (Dutch $x$ Guzerá) were used, 12 males and 12 females, with initial weight of $32.25 \pm 4.8 \mathrm{~kg}$ for females and $36.92 \pm 6.8 \mathrm{~kg}$ for males. The animals were distributed in a completely randomized design, in a factorial scheme $(3 \times 2)$. The calves received water at will and six liters of milk replacer a day for 60 days in three different strategies, called the suckling system (SA-30: 3 liters of milk replacer, twice a day until 30 days of age; SA-45: 3 liters of milk replacer, twice a day until 45 days of age; SA-49: 3 liters of milk replacer, twice daily up to 49 days old). The lactation systems studied did not present statistical difference $(P>0.05)$ for the consumption and digestibility of nutrients, except for organic matter (OM) and ethereal extract (EE). There was an interaction $(P<0.05)$ between the suckling system and sexual class for the OM and EE intakes, as well as for the average daily gain, in which HS 49 males presented higher averages in relation to SA 30. The bioeconomic performance of male calves from the lactation system 49 was superior and presented the best cost-benefit ratio among the systems studied.
\end{abstract}

Keywords: dairy succession, cattle, consumption, performance

Recebido em 22 de dezembro de 2016

Aceito em 22 de novembro de 2017

E-mail: jmedvet@hotmail.com 


\section{INTRODUÇÃO}

O desenvolvimento do gado leiteiro mestiço no Brasil tende aliar a rusticidade com a produção de leite. Dentre as raças zebuínas mais utilizadas para a produção de leite no Brasil, o Gir e o Guzerá, apresentam um dos melhores desempenhos, ganhando adeptos em toda a pecuária nacional (Ribeiroet al., 2009). Nesse contexto, as estratégia de cruzamento entre raças zebuínas e europeias especializadas para a produção de leite, ocorre com o objetivo de aumentar a eficiência produtiva dos animais em condições tropicais (Madalena, 2008).

Os métodos de aleitamento são constantemente estudados para animais da raça Holandesa e revelam que o método tradicional de aleitamento, que utiliza de 8 a $10 \%$ do peso corporal (PC) como base para o fornecimento de quatro litros de leite ou sucedâneo lácteo por dia, está associado ao baixo desempenho, visto que o peso vivo na oitava semana pelo método tradicional situa-se em torno de $71,69 \mathrm{~kg}$ contra $77,64 \mathrm{~kg}$ no aleitamento intensivo (Gomes et al., 2014).

$\mathrm{O}$ aleitamento intensivo se tornou uma opção e apresenta como vantagens a maior taxa de ganho de peso $(0,359 \mathrm{~kg} / \mathrm{dia})$ até a oitava semana e a redução de $11 \%$ nos custos de produção por quilo de ganho (Silperet al., 2014).

A aplicação de tecnologias visa ao aumento da rentabilidade do sistema, e a criação de bezerras é responsável por renovar o rebanho por meio da entrada de novas gerações no sistema de produção, o que eleva a pressão de seleção e o melhoramento genético do rebanho, porém essa fase representa aumento nos custos operacionais, o que demanda atenção no direcionamento de recursos para tal finalidade (Santos e Lopes, 2014).

Objetivou-se avaliar a eficiência bioeconômica de bezerros mestiços, de duas classes sexuais (machos e fêmeas), submetidos a diferentes sistemas de aleitamento nos primeiros 60 dias de idade.

\section{MATERIAL E MÉTODOS}

Esta pesquisa foi aprovada pela Comissão de Ética no Uso de Animais da Universidade Estadual de Santa Cruz (CEUA-UESC), com número de protocolo 020/2015.
Foram utilizados 24 bezerros mestiços (Holandês x Guzerá), sendo 12 fêmeas e 12 machos, lactentes, com idade entre um e 60 dias. O peso corporal inicial foi de $32,25 \pm 4,8 \mathrm{~kg}$ para fêmeas e de $36,92 \pm 6,8 \mathrm{~kg}$ para os machos.

O experimento foi conduzido numa propriedade leiteira comercial, localizada no município de Caravelas, Bahia, a uma latitude $\left(17^{\circ} 42,5^{\prime} 58^{\prime \prime}\right)$ sul e a uma longitude $\left(39^{\circ} 47^{\prime} 10,5^{\prime \prime}\right)$ oeste, em parceria com a Universidade Estadual de Santa Cruz.

Para alojamento de forma individualizada de cada animal, utilizou-se o bezerreiro "tipo tropical", com fornecimento à vontade de água, no qual cada animal ficou preso a uma corrente de $1,2 \mathrm{~m}$ de comprimento, ligadaa uma cordoalha no solo com $7 \mathrm{~m}$ de comprimento, coberta com sombrite de polietileno com $1,5 \mathrm{~m}$ de largura (80\% de interceptação luminosa), fixado em estrutura de madeira, no sentido norte-sul, com altura de 1,60 do solo. Entre os animais, houve a distância de $1 \mathrm{~m}$ quando as correntes estavam esticadas, para que os animais não tivessem contato físico.

Após o parto, os animais (machos e fêmeas) foram separados das mães imediatamente após o nascimento e receberam manejo sanitário. As vacas foram ordenhadas em ordenha mecânica balde ao pé, e o colostro foi coletado e amostrado para avaliação da concentração de imunoglobulinas, com auxílio de um colostrômetro. Quando a concentração de imunoglobulinas estava acima de $50 \mathrm{mg} / \mathrm{mL}$, esse colostro foi fornecido ad libitumaos bezerros, em mamadeira, nas primeiras duas horas de vida (Heinrichs e Jones, 2011).

No segundo dia, os bezerros foram alimentados com leite de transição das respectivas mães, fornecido em mamadeiras de dois litros, ad libtum, às sete horas e às $15 \mathrm{~h}$. Coletaram-se $5 \mathrm{~mL}$ de sangue na veia jugular, em tubo de vidro sem anticoagulante, sendo a amostra centrifugada a 4000rpm, durante 6min, para obtenção do soro. Com auxílio de um refratômetro, determinou-se a concentração de proteínas séricas (Mcbeathet al., 1971; Weaver et al., 2000). Quando o resultado de refratometria foi superior a $5,5 \mathrm{~g}$ de proteína total/dL, considerou-se que os bezerros estariam aptos a entrar no experimento. 
A partir do terceiro dia, iniciou-sea fase de adaptação ao aleitamento em balde plástico. No quarto dia de idade os bezerros foram pesados e distribuídos em delineamento inteiramente ao acaso, em esquema fatorial $(3 \times 2)$, sendo três sistemas de aleitamento e duas classes sexuais (macho e fêmea), com quatro repetições para cada fator.

Foram estudados três sistemas de aleitamento (SA30, SA45 e SA49). No sistema de aleitamento SA30, os animais receberam três litros de sucedâneo lácteo, duas vezes ao dia, até 30 dias de idade; em seguida, receberam seis litros, uma vez por dia, até o desmame, aos 60 dias de idade. No sistema de aleitamento SA45, os animais receberam três litros de sucedâneo lácteo, duas vezes ao dia, até 45 dias de idade; em seguida, receberam seis litros, uma vez por dia, até o desmame, aos 60 dias de idade. No sistema de aleitamento SA49, os animais receberam três litros de sucedâneo lácteo, duas vezes ao dia, até 49 dias de idade; em seguida, receberam seis litros, uma vez por dia, até o desmame, aos 60 dias de idade. Além do leite, todos os animais (SA30, SA45 e SA49) receberam concentrado, de forma individualizada, do quinto aos 60 dias de idade.

O sucedâneo utilizado possuía $95,09 \%$ de matéria seca (MS), 5,99\% de matéria mineral (MM), 20,87\% de proteína bruta (PB), 14,79\% de extrato etéreo (EE) e $1,45 \%$ de fibra bruta (FB). O concentrado foi misturado no local, com a seguinte formulação: $44,8 \%$ de milho integral moído, 34,2\% de farelo de soja, $13 \%$ de farelo de trigo, $4 \%$ de núcleo mineral (Nc Milk Máxima $\mathrm{C}^{\circledR}$ ) e $4 \%$ de palatabilizante (Leite $\mathrm{Mix}^{\circledR}$ ), apresentando $22 \%$ de proteína bruta (PB) e $71 \%$ de nutrientes digestíveis totais (NDT).

Durante a fase de aleitamento, todos os bezerros foram manejados duas vezes ao dia, às sete horas e às $16 \mathrm{~h}$, quando se trocou a água (20 litros), forneceu-se $\mathrm{o}$ sucedâneo $\left(38\right.$ a $\left.42^{\circ} \mathrm{C}\right)$ na quantidade de três litros ou seis litros, conforme o período do sistema de aleitamento estudado, o que permitiu que todos os animais tivessem acesso à mesma quantidade de sucedâneo durante o período de estudo.

O concentrado foi fornecido ad libitum, em proporções crescentes $(250$ a $2000 \mathrm{~g} / \mathrm{dia})$ com o avanço do consumo. As sobras de concentrado foram coletadas, pesadas e amostradas diariamente, sendo identificadas por animal, para posteriormente ser estimado o consumo de nutrientes.

Aos 30, 45 e 60 dias de idade, realizou-se a coleta de fezes; nesse período, também foram realizadas amostragens diárias dos alimentos. Todas as amostras foram devidamente armazenadas e congeladas a $-15^{\circ} \mathrm{C}$ para posteriores análises laboratoriais.

As análises laboratoriais foram realizadas no Laboratório de Pesquisa em Nutrição e Alimentação de Ruminantes (LaPNAR) e no Laboratório de Nutrição Animal, localizado na Universidade Estadual de Santa Cruz (UESC).

As amostras de fezes foram descongeladas à temperatura ambiente e pré-secas em estufa de ventilação forçada à temperatura de $60^{\circ} \mathrm{C}\left( \pm 5^{\circ} \mathrm{C}\right)$, durante 72 horas. Em seguida, foram levadas ao moinho de facas, processadas e padronizadas com peneira de porosidade de $2 \mathrm{~mm}$ de diâmetro, para posteriores análises de matéria seca (MS), proteína bruta $(\mathrm{PB})$, extrato etéreo $(\mathrm{EE})$ e fibra em detergente ácido (FDA) e matéria mineral (MM) (Official..., 1990). Os carboidratos totais (CT) foram estimados de acordo com Sniffenet al. $(1992): \mathrm{CT}=100-(\% \mathrm{~PB}+\% \mathrm{EE}+\%$ cinza $)$. Os nutrientes digestíveis totais (NDT) foram obtidos conforme as equações adotadas pelo NRC (Nutrient..., 2001), em que: NDT = (PBdigestível + CTdigestível $+(2,25$ *EEdigestível)).

Para estimar a produção fecal, foi utilizada a lignina purificada e enriquecida (LIPE ${ }^{\circledR}$ ), como indicador externo (uma cápsula de 250mg/animal/dia). As fezes (50g) foram coletadas diretamente na ampola retal, uma vez por dia, durante cinco dias, em diferentes horários do período de coleta, em cinco horários preestabelecidos: oito horas (primeiro dia), 10h (segundo dia), 12h (terceiro dia), 14h (quarto dia) e $16 \mathrm{~h}$ (quinto dia), compondo, assim, amostras de fezes por animal. O coeficiente de digestibilidade (CD) de cada nutriente foi calculado por: $\mathrm{CD}=$ (nutriente consumido nutriente excretado)/nutriente consumido $* 100$

Os animais foram pesados em balança eletrônica, modelo MGR-4000, antes de receberem a alimentação da manhã, no seguinte esquema: 
pesagens ao nascimento e nos dias cinco, 30, 45 e 60 de idade.

Para cálculo do ganho médio diário (GMD), levou-se em consideração o peso corporal final (PCf) e o peso corporal inicial (PCi), divididos pelo total de dias estudados: GMD $=$ (PCf$\mathrm{PCi}$ )/dias em aleitamento; já para o cálculo da conversão alimentar (CA), considerou-seo consumo de matéria seca (CMS) e o ganho médio diário $(\mathrm{GMD})(\mathrm{CA}=\mathrm{CMS} / \mathrm{GMD})$.

Para compor os custos operacionais, foram considerados os custos com alimentação (sucedâneo e concentrado), mão de obra e medicamentos preventivos e curativos. $\mathrm{O}$ custo operacional foi obtido pela soma das despesas com alimentação, mãodeobra, sanidade, impostos e taxas (Matsunaga e Toledo, 1976; Santos e Lopes, 2014).

O custo de produção final foi calculado dividindo-se a despesa total no período de 54 dias pelo valor comercial final dos animais. Para encontrar o valor comercial dos animais, foi considerado o valor médio da arroba negociado no período, que foi de $\mathrm{R} \$ 160,00$ para fêmeas e de $\mathrm{R} \$ 180,00$ para machos.

Os dados obtidos foram submetidos à análise de variância (Proc GLM), com auxílio do programa StatisticalAnalysis System (Statistical..., 2002), adotando-se o teste Tukey a 5\% como nível crítico de probabilidade para o erro tipo I. Adotou-se como covariável o peso corporal inicial (PCi), para as variáveis peso corporal final (PCF), ganho de peso total (GPT), ganho médio diário (GMD) e conversão alimentar (CA). Utilizou-se o seguinte modelo estatístico para análise dos dados: $\mathrm{Yijk}=\mu+\mathrm{SAi}+\mathrm{CSj}+$ SACSij + Eijk,em que: Yijk= valor observado da característica; $\mu=$ média geral; $\mathrm{SAi}=$ efeito relativo ao sistema de aleitamento $(i=1,2,3)$; $\mathrm{CSj}$ = efeito relativo à classe sexual $(\mathrm{j}=\mathrm{M}, \mathrm{F}) ; \mathrm{SACSij}$ = efeito da interação entre sistema de aleitamento i e a classe sexual j; $\varepsilon i j k=$ erro aleatório, associado a cada observação Yijk.

\section{RESULTADOS E DISCUSSÃO}

Não houve interação $(\mathrm{P}>0,05)$ entre os sistemas de aleitamento e a classe sexual para o consumo de MS, PB, CT e NDT. Assim como não foi verificado diferença estatística $(\mathrm{P}>0,05)$ para $\mathrm{o}$ consumo destes nutrientes, quando avaliou o sistema de aleitamento e a classe sexual de forma isolada. Os valores médios encontrados para consumo de MS, PB, CT, NDT expressos em g/dia e o consumo de MS em kg de peso corporal (PC) e metabólico $\left(\mathrm{PC}^{0,75}\right)$ foram de 719,53; 179,97; 437,02; 587,12g/dia; $1,35 \mathrm{~kg} / \mathrm{kg}$ PC e $36,31 \mathrm{~kg} / \mathrm{kg} \mathrm{PC}{ }^{0,75}$, respectivamente (Tab. 1).

Houve interação $(\mathrm{P}<0,05)$ entre o sistema de aleitamento e a classe sexual para os consumos de MO (g/dia) e EE (g/dia), sendo os maiores consumos observados para os animais machos no sistema de aleitamento 49 (SA 49) em relação ao sistema de aleitamento 30 (SA 30) (Tab. 2).

Tabela 1. Consumo de nutrientes em função do sistema de aleitamento e das classes sexuais

\begin{tabular}{cccccccccc}
\hline \multirow{2}{*}{ Item } & \multicolumn{2}{c}{ Sistema de aleitamento } & \multicolumn{2}{c}{ Sexo } & CV $(\%)$ & \multicolumn{3}{c}{ Valor de P } \\
\cline { 2 - 9 } & SA30 & SA45 & SA49 & F & M & SA & CS & INT \\
\hline \multicolumn{7}{c}{ Consumo g/dia } \\
\hline MS & 614,4 & 663,4 & 836,7 & 686,3 & 723,4 & 46,5 & 0,1202 & 0,7070 & 0,0687 \\
MO & 604,8 & 590,5 & 738,1 & 614,7 & 674,2 & 46,8 & 0,1912 & 0,4450 & 0,0158 \\
PB & 168,6 & 158,9 & 206,6 & 166,4 & 189,7 & 46,3 & 0,1275 & 0,2800 & 0,0527 \\
EE & 59,3 & 58,7 & 67,2 & 61,0 & 62,5 & 23,2 & 0,1093 & 0,6950 & 0,0081 \\
CT & 381,9 & 449,8 & 468,9 & 392,2 & 475,0 & 72,3 & 0,6112 & 0,3040 & 0,0899 \\
NDT & 504,7 & 545,5 & 618,8 & 545,8 & 566,8 & 57,9 & 0,6163 & 0,8420 & 0,1524 \\
\hline \multicolumn{7}{c}{ Consumo kg/kg PC } \\
\hline MS & 1,2 & 1,3 & 1,5 & 1,3 & 1,3 & 34,6 & 0,2120 & 0,989 & 0,0684 \\
\hline \multicolumn{7}{c}{ Consumo g/kg PC } \\
\hline MS & 32,2 & 34,5 & 40,5 & 35,5 & 36,0 & 37,3 & 0,1770 & 0,905 & 0,0664 \\
\hline
\end{tabular}

$\mathrm{MS}=$ matéria seca, $\mathrm{PC}=$ peso corporal, $\mathrm{PM}=$ peso metabólico, $\mathrm{MO}=$ matéria orgânica, $\mathrm{PB}=$ proteína bruta, $\mathrm{EE}=$ extrato etéreo, $\mathrm{CT}=$ carboidratos totais e NDT= nutrientes digestíveis totais. $\mathrm{SA}=$ sistema de aleitamento, $\mathrm{F}=$ fêmea, $\mathrm{M}=$ macho, $\mathrm{CV}=$ coeficiente de variação, $\mathrm{CS}=$ classe sexual e INT= interação. Médias seguidas da mesma letra na linha não diferem $(\mathrm{P}>0,05)$ entre si pelo teste de Tukey. 
Tabela 2. Desdobramento de interação para o consumo de matéria orgânica e extrato etéreo em função do sistema de aleitamento e classe sexual

\begin{tabular}{|c|c|c|c|}
\hline \multirow{2}{*}{ Classe sexual } & \multicolumn{3}{|c|}{ Sistema de aleitamento } \\
\hline & SA 30 & SA 45 & SA 49 \\
\hline \multicolumn{4}{|c|}{ Consumo de MO (g/dia) } \\
\hline $\mathrm{F}$ & 742,3 & 506,3 & 595,6 \\
\hline M & $467,2 \mathrm{~b}$ & $674,7 \mathrm{ab}$ & $880,6 \mathrm{a}$ \\
\hline \multicolumn{4}{|c|}{ Consumo de EE (g/dia) } \\
\hline $\mathrm{F}$ & 67,8 & 54,1 & 61,0 \\
\hline M & $50,8 \mathrm{~b}$ & $63,3 \mathrm{ab}$ & $73,3 \mathrm{a}$ \\
\hline
\end{tabular}

$\mathrm{MO}=$ matéria orgânica, $\mathrm{EE}=$ extrato etéreo, $\mathrm{PC}=$ peso corporal, $\mathrm{F}=$ fêmea, $\mathrm{M}=$ macho. Médias seguidas da mesma letra na linha não diferem $(\mathrm{P}>0,05)$ entre si pelo teste de Tukey.

Os sistemas de aleitamento possibilitaram que todos os animais tivessem acesso à mesma quantidade de sucedâneo durante o período de estudo, o que não permitiu que o desempenho fosse afetado pelo balanceamento nutricional e o consumo de nutrientes sofresse interferência. Outras estratégias de aleitamento são descritas com variação das quantidades de sucedâneo fornecido em diferentes momentos, o que afeta o consumo de nutrientes (Silperet al., 2014).

No presente estudo, os nutrientes foram oferecidos por meio do sucedâneo lácteo e de concentrado. O consumo médio de MS observado para os SA 30, SA 45 e SA 49 foi correspondente a $1,35 \%$ do PC. O peso vivo é constantemente relacionado com a quantidade de nutrientes que deve ser fornecida aos bezerros, e protocolos de aleitamento foram propostos com esse objetivo, por meio do uso de $1,5 \%$ do peso vivo/dia na primeira semana de idade e $2 \%$ do peso vivo na segunda semana de idade até o desmame, utilizando-se bezerros da raça Holandesa com $43,5 \mathrm{~kg}$ de peso inicial (Stameyet al., 2012).

Provavelmente, o menor consumo de MS (\% PC) encontrado nesta pesquisa foi devido ao inferior peso inicial dos bezerros e à alta densidade energética da dieta, com baixa fibra, que foram suficientes para atender as demandas energéticas dos animais.

Apesar de o consumo de concentrado ser maior em bezerros alimentados com menor volume de sucedâneo após os primeiros 30 dias, o crescimento dos bezerros que recebem maiores quantidades de sucedâneo é mais acelerado, devido à maior ingestão de energia e proteína (Bach et al., 2013).
Observou-se que consumo médio de MS, PB, CT, NDT e consumo de MS/kg de PC estão de acordo com dados relatados por outros autores em estudos com inclusão de seis litros de sucedâneo de leite (Bach et al., 2013). Estes autores também relataram aumento do consumo com o passar da idade.

Outras estratégias foram avaliadas por Leão et al. (2013), que avaliaram bezerras mestiças, em três grupos com diferentes volumes de leite, em períodos variáveis $(\mathrm{G} 1$ - 6L-45d/4L-60d/2L90d), (G2 - 6L-30d/4L-60d/2L-90d) e (G3 - 8L30d/6L-60d/3L-90d). Em concordânciacom outros estudos, o fator que continuou sendo apontado como responsável pelo melhor desempenho dos bezerros foi o maior volume de leite (G-3), que também influenciou negativamente o consumo de alimentos sólidos.

Nota-se, com base na referida literatura, que o aleitamento é primordial para o melhor desempenho dos animais. Independentemente do aumento do consumo de concentrado na fase inicial, o maior desenvolvimento dos animais foi influenciado pelo maior consumo de nutrientes oriundo do aleitamento,o que possibilitoumelhores taxas de crescimento aos bezerros e maiores ganhos de peso.

O maior consumo de $\mathrm{MO}$ e EE encontrado nos animais machos no SA 49 pode ser explicado pelo maior consumo de nutrientes observado neste grupo.O fracionamento da oferta por um período maior provavelmente melhorou a digestão dos componentes da dieta e o consumo de alimentos sólidos.

Não houve interação $(\mathrm{P}>0,05)$ entre o sistema de aleitamento e as classes sexuais para a 
digestibilidade dos nutrientes e o NDT, bem como não foram verificadas diferença estatística $(\mathrm{P}>0,05)$ para estas variáveis, quando se avaliou o sistema de aleitamento e a classe sexual de forma independente, sendo os valores médios, percentuais, observados para a digestibilidade da MS,daMO, da PB, do EE, do CT edo NDT de 67,$2 ; \quad 67,86 ; \quad 74,48 ; 86,63 ; 62,58$ e 74 , respectivamente (Tab. 3 ).

Tabela 3. Digestibilidade dos nutrientes em função do sistema de aleitamento e das classes sexuais

\begin{tabular}{|c|c|c|c|c|c|c|c|c|c|}
\hline \multirow{2}{*}{ Item } & \multicolumn{3}{|c|}{ Sistemas de aleitamento } & \multicolumn{2}{|c|}{ Classe sexual } & \multirow{2}{*}{$\mathrm{CV}(\%)$} & \multicolumn{3}{|c|}{ Valor de P } \\
\hline & SA30 & SA45 & SA49 & $\mathrm{F}$ & $\mathrm{M}$ & & SA & CS & INT \\
\hline MS & 65,3 & 62,1 & 70,6 & 65,1 & 66,9 & 17,7 & 0,1031 & 0,6088 & 0,0510 \\
\hline MO & 67,1 & 62,8 & 71,0 & 66,1 & 67,8 & 16,7 & 0,1142 & 0,6156 & 0,1660 \\
\hline $\mathrm{PB}$ & 72,8 & 73,7 & 75,3 & 73,9 & 74,0 & 14,8 & 0,8159 & 0,9865 & 0,4938 \\
\hline $\mathrm{EE}$ & 81,8 & 84,2 & 90,9 & 84,6 & 86,7 & 15,3 & 0,1245 & 0,5824 & 0,5778 \\
\hline $\mathrm{CT}$ & 61,6 & 58,2 & 65,4 & 60,7 & 62,8 & 21,4 & 0,2986 & 0,6157 & 0,1605 \\
\hline NDT & 72,7 & 70,0 & 75,5 & 71,4 & 74,0 & 15,1 & 0,3849 & 0,4542 & 0,2509 \\
\hline
\end{tabular}

$\mathrm{MS}=$ matéria seca, $\mathrm{MO}=$ matéria orgânica, $\mathrm{PB}=$ proteína bruta, $\mathrm{EE}=$ extrato etéreo, $\mathrm{CT}=$ carboidratos totais e $\mathrm{NDT}=$ nutrientes digestíveis totais. $\mathrm{SA}=$ sistema de aleitamento, $\mathrm{F}=$ fêmea, $\mathrm{M}=$ macho, $\mathrm{CV}=$ coeficiente de variação, $\mathrm{CS}=$ classe sexual e INT= interação. Médias seguidas da mesma letra na linha não diferem $(\mathrm{P}>0,05)$ entre si pelo teste de Tukey.

A semelhança entre os sistemas de aleitamento para o coeficiente digestibilidade aparente dos nutrientes deve-se, possivelmente, ao fato de esses sistemas de aleitamento não apresentarem diferença na composição da dieta fornecida e no consumo da maioria dos nutrientes; apenas foi estudada a variação de consumo com base na estratégia de fornecimento, e o maior consumo de MO observado nos machos do SA $49 \mathrm{em}$ comparação com o SA 30 não contribuiu para redução da digestibilidade (Tab. 3).

O sistema de aleitamento, independentemente da classe sexual, influenciou $(\mathrm{P}<0,05)$ o peso corporal final (Tab. 4). As maiores médias para os pesos finais $(\mathrm{P}<0,05)$ foram verificadas nos bezerros que foram submetidos ao sistema de aleitamento 49 (SA 49)em relação ao sistema de aleitamento 30 (SA 30). Não houve diferença $(\mathrm{P}>0,05)$ no peso final dos bezerros no sistema de aleitamento 45 (SA 45) em relação aos bezerros dos demais sistemas de aleitamento (Tab. 4).

Observou-se interação $(\mathrm{P}<0,05)$ entre o sistema de aleitamento e a classe sexual para o ganho médio diário (GMD). Os bezerros que foram submetidos ao SA 49 apresentaram maior ganho de peso em relação aos animais do SA 30, entretanto os animais que foram submetidos ao SA 45 não diferiram dos demais sistemas de aleitamento (Tab. 5).

Tabela 4. Desempenho de bezerros mestiços em função do sistema de aleitamento e das classes sexuais

\begin{tabular}{|c|c|c|c|c|c|c|c|c|c|}
\hline \multirow{2}{*}{ Item } & \multicolumn{3}{|c|}{ Sistemas de aleitamento } & \multicolumn{2}{|c|}{ Classe sexual } & \multirow{2}{*}{$\mathrm{CV}(\%)$} & \multicolumn{3}{|c|}{ Valor de $\mathrm{P}$} \\
\hline & SA30 & SA45 & SA49 & $\mathrm{F}$ & $\mathrm{M}$ & & AS & CS & INT \\
\hline PF & $49,4 b$ & $50,9 \mathrm{ab}$ & $55,2 \mathrm{a}$ & 50,4 & 53,3 & 13,4 & 0,0453 & 0,1783 & 0,0637 \\
\hline GMD & 379,0 & 387,8 & 549,4 & 414,4 & 463,0 & 45,0 & 0,0228 & 0,4174 & 0,0452 \\
\hline $\mathrm{CA}$ & 1,7 & 1,8 & 1,6 & 1,7 & 1,7 & 26,8 & 0,5262 & 0,6398 & 0,7917 \\
\hline
\end{tabular}

$\mathrm{SA}=$ sistema de aleitamento, $\mathrm{F}=$ fêmea, $\mathrm{M}=$ macho, $\mathrm{CV}=$ coeficiente de variação, $\mathrm{CS}=$ classe sexual e INT = interação. Peso final (PF), ganho médio diário (GMD) e conversão alimentar (CA) em função do sistema de aleitamento e das classes sexuais.

Médias seguidas da mesma letra na linha não diferem $(\mathrm{P}>0,05)$ entre si pelo teste de Tukey. 
Sistemas de aleitamento...

Tabela 5. Desdobramento da interação para o ganho médio diário em função do sistema de alimentação e classe sexual

\begin{tabular}{cccc}
\hline & \multicolumn{3}{c}{ Sistema de aleitamento } \\
\hline Classe sexual & SA 30 & SA 45 & SA 49 \\
\hline F & & Ganho médio diário (g/dia) & \\
M & 464,7 & 326,7 & 452,0 \\
& $293,2 \mathrm{~b}$ & $448,8 \mathrm{ab}$ & $646,9 \mathrm{a}$ \\
\hline
\end{tabular}

$\mathrm{GMD}=$ ganho médio diário, $\mathrm{F}=$ fêmea, $\mathrm{M}=$ macho. Médias seguidas da mesma letra na linha não diferem $(\mathrm{P}>0,05)$ entre si pelo teste de Tukey.

A quantidade de sucedâneo lácteo fornecido foi igual (324L) para os três sistemas de aleitamento, e esperava-se que o consumo de nutrientes fosse afetado apenas pela estratégia de fornecimento, resultado que não foi observado (Tab. 1). Silperet al. (2014) encontraram maior ganho de peso em bezerros Holandeses machos alimentados com maior quantidade (360L) de sucedâneo lácteo durante a fase prédesaleitamento, em comparação com duas estratégias de aleitamento com menor volume de sucedâneo (240L e 298L).

Em estudo realizado por Bach et al. (2013), o crescimento dos bezerros que receberam $8 \mathrm{~L}$ de sucedâneo lácteo em comparação com o grupo que recebeu $6 \mathrm{~L}$ foi maior até o desaleitamento $(72,6 \mathrm{~kg} \sim 68,9 \mathrm{~kg})$. O volume de $6 \mathrm{~L}$ estudado no presente estudo é igual ao utilizado por estes autores, entretanto o peso ao desaleitamento foi menor (Tab. 4), podendo ser explicado pela raça (Holandês) com peso inicial maior $(41,7 \mathrm{~kg}) \mathrm{e}$ estratégia de aleitamento, em que os bezerros foram mantidos de forma individual até 52 dias de idade, em seguida agrupados (10 bezerros), e receberam ração de desmama ad libtum e $2 \mathrm{~L}$ de sucedâneo até o desmame completo, aos 73 dias (Bach et al., 2013).

Bach et al. (2013) e Azevedo et al. (2014) observaram que a redução do volume de leite fornecido após 25 dias de idade favoreceu o aumento no consumo de concentrado e resultou em maior consumo de MS total. O SA 30 objetivou o aumento do consumo de sólidos a partir dos 30 dias, devido à estratégia de fornecimento do sucedâneo apenas pela manhã, estimulando a busca pelo concentrado,efeito este que não foi observado $(\mathrm{P}>0,05)$.

O maior ganho de peso observado no sistema de aleitamento 49 pode ser explicado pela estratégia de aleitamento, pois o volume de leite fornecido em duas frações diárias permitiu aos animais aumentar o consumo de concentrado gradativamente. Além disso, a oferta de alimento fracionado em um período mais longo, provavelmente, melhorou a digestão dos componentes da dieta e o consumo de alimentos sólidos.

$\mathrm{Na}$ avaliação econômica dos sistemas de aleitamento, observou-se que a menor despesa operacional foi encontrada para o SA 45, em comparação com o SA 30 e o SA 49, entretanto o custo por quilograma ao final do período foi menor para os animais machos do sistema de aleitamento 49 (Tab. 6).

Em relação ao custo de produção, observou-se que a mão de obra é um fator importante na composição dos custos estudados. Para Schiffleret al. (1999), esse custo deve ser separado entre a mão de obra despendida para produção de leite e aquela utilizada na cria e recria dos animais, além de outras despesas produtivas.

Os resultados encontrados nos sistemas de aleitamentos estudados demonstram que os ganhos produtivos tornam o sistema mais eficiente, tanto em termosprodutivosquanto econômicos. Lopes et al. (2007) consideram que a apuração de custos, dividindo-se as despesas pela metodologia de "centros de custos", possibilita maior precisão em relação às análises do custo total médio na pecuária leiteira.

Nas fêmeas do SA 30 e do SA 49, foi observado ganho de peso acima de $450 \mathrm{~g} /$ dia. Existe uma correlação entre o ganho de peso diário antes do desaleitamento e a produção de leite em novilhas leiteiras.Essa relação foi proposta por Van Amburghet al. (2005), segundo a qual $450 \mathrm{~g}$ de ganho de peso diário representam o acréscimo de $450 \mathrm{~kg}$ de leite na primeira lactação. 
Tabela 6. Avaliação econômica do custo por quilograma de peso ganho em bezerros mestiços, com base no consumo de matéria seca e na despesa operacional em função do sistema de aleitamento e da classe sexual

\begin{tabular}{ccccc}
\hline \multirow{2}{*}{ Item } & CS & \multicolumn{3}{c}{ Sistema de aleitamento } \\
\cline { 3 - 5 } & & SA30 & SA45 & SA49 \\
\hline \multirow{2}{*}{ Alimentar diário (R\$) } & F & 5,50 & 5,48 & 5,59 \\
& M & 5,50 & 5,48 & 5,59 \\
Custo alimentar (R\$) & F & 297,00 & 295,92 & 301,86 \\
Custo da mão de obra (R\$) & M & 297,00 & 295,92 & 301,86 \\
& F & 15,97 & 15,97 & 15,97 \\
Despesa total (R\$) & F & 15,97 & 15,97 & 15,97 \\
& M & 312,97 & 311,89 & 317,83 \\
GMD (g) & F & 312,97 & 311,89 & 317,83 \\
& M & 464,69 & 326,69 & 451,96 \\
Peso final (kg) & F & 293,22 & 448,83 & 646,91 \\
& M & 51,46 & 48,62 & 51,24 \\
Valor comercial final (R\$) & F & 47,38 & 53,15 & 59,26 \\
Saldo financeiro (R\$) & M & 274,45 & 259,31 & 273,28 \\
& F & 284,28 & 318,90 & 355,56 \\
Custo/peso final (R\$) & M & $-38,52$ & $-52,58$ & $-44,55$ \\
& F & $-28,69$ & 7,01 & 37,73 \\
& M & 1,14 & 1,20 & 1,16 \\
\end{tabular}

$\mathrm{SA}=$ sistema de aleitamento, $\mathrm{CS}=$ classe sexual, $\mathrm{GMD}=$ ganho médio diário, $\mathrm{CMS}$ = consumo de matéria seca, $\mathrm{F}=$ fêmea, $\mathrm{M}=$ macho.

Quanto aos machos, apenas os animais do SA 49 apresentaram ganho de peso superior a $450 \mathrm{~g}$, entretanto os conceitos acima discutidos não se aplicam a essa classe sexual. Ribeiro et al. (2001) indicam a possibilidade de aproveitamento dos bezerros provenientes de raças produtoras de leite para produção de carne. Essa alternativa é a mais viável para os machos mestiços do SA 49, pois o ganho de peso observado foi de $646,91 \mathrm{~g} / \mathrm{dia}$ e houve margem financeira positiva nesse grupo estudado.

É possível afirmar que há viabilidade econômica para a cria, recria e terminação dos machos mestiços do SA 49 com base nesses dados. Alves et al. (2004) estudaram o desempenho de bezerros mestiços Holandês x Guzerá nas fases de recria e terminação e encontraram desempenho produtivo semelhante a animais zebuínos, com ganhos médios de $1,4 \mathrm{~kg} /$ dia na fase de recria e de $0,960 \mathrm{~kg} /$ dia na terminação e menor custo com alimentação por quilo de peso corporal produzido na fase de cria $(\mathrm{R} \$ / \mathrm{kg} 1,31)$.

\section{CONCLUSÕES}

Os sistemas de aleitamento com fornecimento de sucedâneo lácteo SA30, SA45 e SA49 e a classe sexual não influenciam o consumo e a digestibilidade da maioria dos nutrientes.
Recomenda-se o sistema de aleitamento 49, uma vez que ele proporciona superior desempenho bioeconômico de bezerros machos e melhor relação custo-benefício entre os sistemas estudados.

\section{REFERÊNCIAS}

ALVES, D.D.; PAULINO, M.F.; BACKES, A.A. et al. Características de carcaça de bovinos Zebu e cruzados Holandês-Zebu. Rev. Bras. Zootec., v.33, p.1274-1284, 2004.

AZEVEDO, R.A.D.; RUFINO, S.R.D.A.; DUARTE, D.V.L. et al. Desempenho de bezerros leiteiros em aleitamento artificial convencional ou fracionado. Rev. Bras. Saúde Prod. Anim., v.15, p.237-247, 2014.

BACH, A.; TERRÉ, M.; PINTO, A. Performance and health responses of dairy calves offered different milk replacer allowances. $J$. DairySci., v.96, p.7790-7797, 2013.

GOMES, I.P.O.; ARRUDA CÓRDOVA, H. et al. Aleitamento intensificado para bezerros da raça holandesa: desempenho, consumo, conversão alimentar e escore de consistência fecal. Arch. Vet. Sci., v.19, p.65-71, 2014. 
HEINRICHS, J.; JONES, C. Colostrum management tools: hydrometers and refractometers. Penn State Extension, 2011. Disponível:https://extension.psu.edu/colostrumm anagement-tools-hydrometers-andrefractometers. Acessado em: 20 de março de 2015.

LEÃO, J.M.; COELHO, S.G.; LANA, A.M.Q. Efeito de três estratégias de aleitamento sobre ganho de peso e consumo de concentrado em bezerras. In: MOSTRA CIENTÍFICA DE PRODUÇÃO ANIMAL DO NORTE DE MINAS GERAIS, 1., 2013, Montes Claros. Anais... Montes Claros: ICA, 2013. p.62-66.

LOPES, P.F.; REIS, R.P.; YAMAGUCHI, L.C.T. Custos e escala de produção na pecuária leiteira: estudo nos principais estados produtores do Brasil. Rev. Econ. Sociol. Rural, v.45, p.567590, 2007.

MADALENA, F.E. Estratégias de uso de recursos genéticos visando melhorar a qualidade do leite e derivados. SIMPÓSIO BRASILEIRO DE MELHORAMENTO ANIMAL, 7., 2008, São Carlos. Anais... São Carlos: SBMA, 2008, v.10, 15p.

MATSUNAGA, M.B.; TOLEDO, P.F. Metodologia de custo de produção utilizada pelo IEA. Agric. São Paulo, v.23, p.123-139, 1976.

McBEATH, D.G.; PENHALE, W.J.; LOGAN, E.F. An examination of the influence of husbandry on the plasma immunoglobulin level of the newborn calf, using a rapid refractometer test for assessing immunoglobulin content. Vet. Rec., v.88, p.266-270, 1971.

NUTRIENT requirement in dairy cattle. 7.ed. Washington: National Academy of Science, 2001. 381p.

OFFICIAL methods of analysis. 15.ed. Arlington, Virginia: AOAC, 1990. v.1, p.1117.

RIBEIRO, T.R.; PEREIRA, J.C.; OLIVEIRA, M.V.M.D. et al. Características da carcaça de bezerros holandeses para produção de vitelos recebendo dietas com diferentes níveis de concentrado. Rev. Bras. Zootec., v.30, p.21542162, 2001.
RIBEIRO, A.B.; TINOCO, A.F.F. et al. Produção e composição do leite de vacas Gir e Guzerá nas diferentes ordens de parto. Revista Caatinga, vol. 22, p.46-5, 2009.

SANTOS, G.; LOPES, M.A. Custos de produção de fêmeas bovinas leiteiras do nascimento ao primeiro parto. Ciênc. Anim. Bras., v.15, p.1119, 2014.

SCHIFFLER, E.A.; MÂNCIO, A.B.; GOMES, S.T.; QUEIROZ, A.C.D. Efeito da escala de produção nos resultados econômicos da produção de leite B no Estado de São Paulo. Rev. Bras. Zootec., v.28, p.425-431, 1999.

SILPER, B.F.; LANA, A.M.Q.; CARVALHO, A.U. et al. Effects of milk replacer feeding strategies on performance, ruminal development, and metabolism of dairy calves. J. Dairy Sci., v.97, p.1016-1025, 2014.

SNIFFEN, C.J.; O'CONNOR, J.D.; VAN SOEST, P.J. et al. A net carbohydrate and protein system for evaluating cattle diets. II. Carbohydrate and protein availability. J. Anim. Sci., v.70, p.3562-3577, 1992.

STAMEY, J.A.; JANOVICK, N.A.; KERTZ, A.F.et al.Influence of starter protein content on growth of dairy calves in an enhanced early nutrition program. J. Dairy Sci. v.95, p.33273336, 2012.

STATISTICAL analysis system. Version9.2. Cary: SAS Institute, 2002.

VAN AMBURGH, M.; DRACKLEY, J.A.M.; GARNSWORTHY, P.C. Current perspectives on the energy and protein requirements of the preweaned calf. In: Calf and heifer rearing: principles of rearing the modern dairy heifer from calf to calving. 60th University of Nottingham Easter School in Agricultural Science, Nottingham University Press, 2005. p.67-82.

WEAVER, D.M.; TYLER, J.W.; VANMETRE, D.C. et al. Passive transfer of colostral immunoglobulins in calves. J. Vet. Intern. Med., v.14, p.569-577, 2000. 